\title{
Exploration on Domestic Flight Delay and Compensation
}

\author{
Jun Zhang \\ ${ }^{1}$ Department of Social Science of the Civil Aviation Flight University of China, Guanghan Sichuan 618307, China \\ ${ }^{2}$ College of Law, Chongqing University, Chongqing 400044, China \\ E-mail: junpinghan@126.com
}

\begin{abstract}
Flight delay refers to the state of facts that, during the aviation passenger transportation, the carrier cannot draw out of station or arrive at the station according to the transport contract. Flight timetable or time specified on the air ticket should be considered as the direct evidence for flight delay. According to the reason of delay, it can be divided as the reasonable delay and unreasonable delay. In principle, the former shall not undertake the responsibility of compensation; the latter shall undertake the responsibility of compensation if the flight is delayed for over 2 hours (including 2 hours). However, no matter which reason leads to the flight delay, the carrier cannot be exempted from the obligation of notification and remedy specified by the law.
\end{abstract}

Keywords-Domestic Flight; Flight Delay; Compensation; Air Passenger; Compensation

\section{INTRODUCTION}

To travel by air, passengers aim at safety, convenience and comfort. However, the high flight delay is still quite common in Chinese civil aviation industry. (See chart) In recent years, with the rapid development of Chinese civilian industry, the flight delay has become the focus of social hot spot, difficulty of civil aviation and focus of passengers. Although passengers do not take the plane for compensation, the flight delay will cause loss. Their final right of claim may not be guaranteed, thus the depression can be imagined. Because the international airlines involve many factors, including international aviation convention, bilateral aviation agreement and nationality of client, location and lawsuit site's law, there are great differences in the aspect of law application, compared to the domestic flight. In this paper, it plans to explore the domestic flight delay and the compensation problem.

2010-2015 National Passenger Transport Volume and Flight Normal

\begin{tabular}{|c|c|c|c|c|c|}
\hline Year & Passenger & Annual & Total & & Flight \\
& transport & growth & flight & Normal & normal \\
volume & rate & $\begin{array}{c}\text { rate } \\
\text { (million) }\end{array}$ & flight & $(\%)$ \\
& (million) & $(\%)$ & & (million) & \\
\hline & & & & & \\
\hline
\end{tabular}

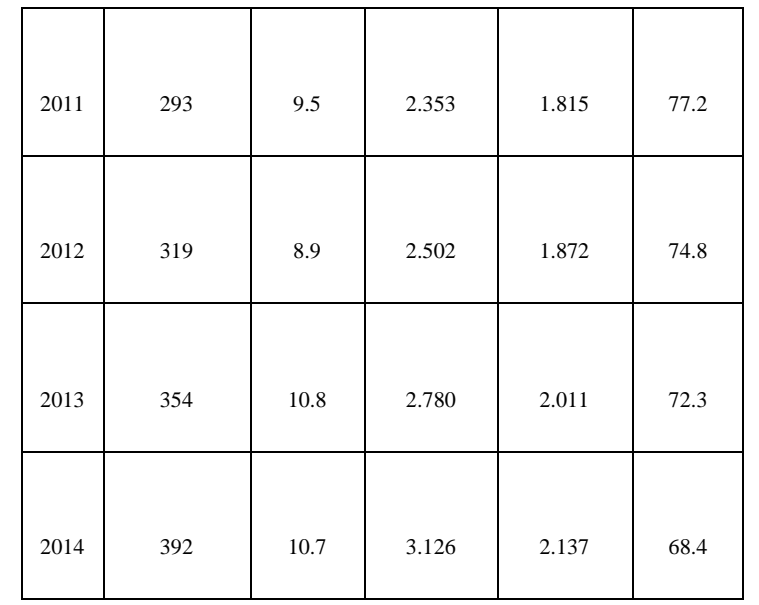

(Note: Data sources from the Development Planning Department of the Civil Aviation Administration of China, 2010-2014 statistical bulletin on the development of civil aviation industry. )

\section{PART ONE DEFINITION OF BASIC PROBLEMS OF FLIGHT DELAY}

\section{A. Concept of Flight Delay}

According to No.126 article of China Civil Aviation Law (hereinafter referred to as Civil Aviation Law) implemented since 1996, "as losses of passenger, baggage or freight caused by delay during aviation transportation, the carrier should undertake responsibilities; however, if the carrier proves that, in order to avoid the loss, the carrier, employee or agent have already taken all necessary measures or they cannot take measures, they shall not undertake the responsibilities." No. 3 article of Domestic Transportation Rule makes explanations for 28 terms in the rule. It is regretful that there is no explanation of "flight delay" and it just displays special services of flight delay in the chapter of "service of abnormal flight". From Warsaw Convention in 1929 to Convention Unifying Some Rules of Aviation Transportation (namely the Montreal Convention) in 1999, the international aviation transportation convention makes principle stipulation about the flight delay and responsibilities to be undertaken, but does not specifically define the concept of flight delay.

The key point to judge the flight delay is to see whether the carrier completes the transportation is in accordance with the time appointed in the contract. As the time appointed in the transportation contract, it usually refers to that stated on the carrier's timetable or air ticket. Since the flight has specified that "regular flight" just refers to the flight having concrete departure time. The 
flight delay can be identified as that the carrier does not transport passengers or baggage to the destination according to the timetable or time stated on the air ticket. ${ }^{[1]}$

In order to make the concept of flight delay have a clear definition, with strong operability, the author thinks that, the flight delay can be defined as this: flight delay refers to one state of facts that the carrier cannot draw out of the station or arrive at the station in accordance with the agreement during the aviation transportation. Flight delay is divided into departure delay and arrival delay. The flight's departure time is delayed and the final arrival time is not delayed, it is called delay; the flight's departure time is not delayed and the final arrival time is delayed, it is called delay as well; the departure and arrival time are both delayed, it must be a delay.

So-called departure delay refers to that the carrier cannot draw out of the station at the time stated on the timetable or air ticket. According to No.28 provision, article 3 of Domestic Transportation Rule, "departure time refers to the time when the aircraft door is closed after all passengers are getting aboard." So-called arrival delay refers to that the carrier cannot arrive at the station according to the time stated on the timetable or air ticket. The current law does not specify the standard for judging the arrival time. Some scholar considers that, the corresponding departure time should be understood as the time opening the aircraft door. The author agrees with such a viewpoint.

\section{B. Legal Force of Time Stated on the Flight Timetable} or Air Ticket

IATA formulated the General Conditions for Passenger and Baggage Transportation in 1972, which specifies that: the passenger ticket is the preliminary evidence proving that a transportation contract exists between the carrier and passenger, as stated by the carrier on the passenger ticket; the carrier undertakes obligations and tries his best to reasonably and rapidly transport passengers and baggage. However, time stated on the flight timetable or other places cannot be guaranteed, which does not constitute part of the contract. If the carrier does not abide by the stated time, it will not be a breach of contract. General Conditions for Passenger and Baggage Transportation formulated by the carrier have similar regulations. Scholar of Aviation Law Zhao Weitian considers that: generally speaking, the delay of Article 19 in Warsaw Convention does not refer to the "delay" of time when the flight draws out of or arrive at the destination, but refers to the expected reasonable deadline that passengers or shippers select the rapid aviation transportation method. [2] Scholar of Aviation Law Dong Nianqing considers that, flight delay of aviation refers to that, the carrier spends more time on transportation than the reasonable time which is required to complete the transportation under normal circumstance. ${ }^{[3]}$

Scholars define the flight delay from the constitution of flight delay responsibility. However, a "reasonable" delay is delay. It is the fact. Just because the carrier does not have to undertake the legal responsibility in accordance with the convention or domestic law under such a circumstance, it should be also judged as delay. Here, the author defines the concept of flight delay according to the normal meaning, and then explore the responsibility on that basis. Article 299 of the PRC
Contract Law (hereinafter referred to as Contract Law) specifies that, "The carrier should transport passengers according to the time stated on the passenger ticket and timetable. In case of delayed transportation, it should arrange passengers to take another plane or refund the ticket according to requirements of passengers." It is applicable to whether the aviation passenger transportation constitutes the delay as well. The flight time marked on the air ticket undoubtedly constitutes the reasonable expectation of the time within which the carrier implements the contract's obligations. It should be considered as the basis for judging whether the carrier constitutes the flight delay. [4]

As far as the author's concerned, the flight timetable or time stated on the air ticket should be judged as the direct evidence for flight delay. Of course, not all carriers conducting flight delays should undertake legal responsibilities. Moreover, according to the reasons for delay, it shall differentiate whether it is a reasonable delay or unreasonable delay, so as to specify the responsibility scope of carrier based on the type of delay. It belongs to another problem, which will be discussed later.

\section{Rationality of Flight Delay}

Aviation transportation is a quite complicated production process. The aviation transportation's particularity of high-technology and risk lead to quite complicated reasons for flight delay. Normal Statistics Method of Civil Aviation specifically lists several reasons for flight delay, such as weather, flow control, maintenance engineering, airport facilities, flight guarantee, flight crew, company's plan, security check, ground accident, passenger, air defense. All these are just fact reasons, which do not distinguish the carrier reason from the non-carrier reason, the subjective reason from the objective reason. It just means that reasons are listed, without involvement of responsibility.

The author agrees to divide the flight delay into reasonable delay and unreasonable delay, based on reasons resulting in delay. [5] Flight delays caused by uncontrollable factors, such as the weather, air control, flow control, accident and security check, belong to reasonable delays. However, delays caused by flight allocation, maintenance, material guarantee and flight crew, belong to unreasonable delays, because the carrier should foresee and avoid them.

Unreasonable delay fatherly defines the reasonable delay time and unreasonable delay time. Here, it should mainly consider the current situation of China's aviation transportation. In order to balance the benefits of air carriers, it should offer reasonable delay time as the transition period, and properly shorten the time period, until it is canceled. Reasonable definition of delay time should take the general rationality as the precondition. First of all, flight departure time and arrival time formulated by the airline are important basic points for reference. Secondly, it should consider the passenger's rational expectation of the airline's convenience. Most voyages of Chinese domestic flights can be completed within 2 hours. It will not be rational if the delay achieves 2 hours or above. Of course, no matter which reason leads to the delay, the airlines cannot be exempted from the obligation of notification or remedy specified by the law. 
Such obligations belong to the attached obligations in the transportation contract of aviation passengers.

\section{PART TWO CONSTRUCTION OF DAMAGE COMPENSATION SYSTEM FOR FLIGHT DELAY}

Civilian Aviation Law and Domestic Transportation Rule make principle regulations on the flight delay. Under the circumstance of flight delay, passengers enjoy the right to know, select and claim. Once the flight delay occurs, it is one of the most common and important remedy for breach of contract: the carrier undertakes the responsibility of compensation. As compensation for flight delay, the current legal basis is Article 126 of Civilian Aviation Law, "as losses of passenger, baggage or freight caused by delay during aviation transportation, the carrier should undertake responsibilities; however, if the carrier proves that, in order to avoid the loss, the carrier, employee or agent has already taken all necessary measures or they cannot take measures, they shall not undertake the responsibilities." Article 126 of Civilian Aviation Law endows the airlines with liability exemption, which are often cited as the powerful basis by the airlines to evade their own responsibilities in case of flight delay. Such an article is too principled and abstract. There is no related enforcement regulation or rule to make further refinement. It leads to constant disputes between the passenger and airline after the occurrence of flight delay, which affects the healthy development of Chinese aviation transportation industry.

The author considers that the components of flight delay compensation can be specifically defined as: (1) flight delay is not caused by force majeure; (2) it surpasses the departure or arrival time stated on the flight timetable or air ticket; (3) it is delayed for two hours or above. (If the carrier does not take any measures after the delay, it is not limited by the time and the carrier must undertake the compensation responsibility)

\section{A. Compensation for Reasonable Delay}

In principle, the reasonable delay does not undertake the compensation responsibility. If the carrier does not take any measure to make up for losses of passengers after the delay, it should undertake the compensation responsibility. According to rules of Warsaw Convention or Civilian Aviation Law, the precondition of liability exemption of carrier is that "all necessary measures have already been adopted for avoiding the losses, or such measures cannot be taken". Under the circumstance of reasonable delay, the carrier needs not to undertake any responsibility for the delay itself. However, if it does not fulfill the obligation of a diligent, responsible and good manager, so as to avoid the losses, it should also undertake corresponding legal responsibilities. In Article 117 of China's Contract Law, "Due to force majeure, the contract cannot be fulfilled, according to impacts of force majeure, part or all responsibilities should be exempted, except as otherwise provided by law." Moreover, as several reasons constituting reasonable delay, if it takes the standard of "unpredictable, unavoidable and unbeatable objective situation" to measure that, only part conforms to the condition.

Under the circumstance of reasonable delay, the carrier shall not undertake any compensation responsibility for the actual economic losses of passenger, baggage or cargo. Because it is one kind of contract relationship between the carrier, passenger and consignor, the collateral obligation of contract determines that, the duty of diligence is not exempted, the carrier should fulfill necessary obligation of notification, arrange accommodations, provide foods, transportation and communication conditions for delayed passengers, or arrange them to take planes of other airlines; and also have the obligation of well keeping registered cargo and luggage. If the carrier does not fulfill the obligation of diligence or prudence, it should undertake corresponding legal responsibilities. Under the circumstance of reasonable delay, according to the principle of honesty and credibility and reasonable requirements of passengers, it should determine whether the carrier has adopted "all necessary measures", namely to inspect the scope of carrier's collateral obligation of contract.

\section{B. Compensation for Unreasonable Delay}

The author holds the opinion that: unreasonable delay surpasses 2 hours (included), the carrier should undertake the compensation responsibility. In case of no corresponding measures, the flight is delayed less than two hours, it cannot be exempted form the compensation responsibility. The carrier must undertake corresponding remedy obligation during the entire time period. Specifically speaking, if the flight delay is not caused by force majeure, then the carrier cannot ask for the exemption plea by "all necessary measures have already been adopted, or such measures cannot be taken", but should undertake corresponding legal responsibilities. However, it should be noted that, if the carrier does not adopt any possible remedies after the unreasonable delay, further to lead to losses of passengers, it should undertake the compensation responsibility during all the period. If it can be proved that the damages caused by flight delay are because of the careless behavior or non-action, the carrier knows that it may result in losses on purpose, it should undertake the compensation responsibility during all the period. Under the circumstance of unreasonable delay, the carrier should compensate actual economic losses of passengers or consignors.

\section{WHETHER IT COMPENS ATES FOR INDIRECT LOSS}

In principle, the indirect loss caused by flight delay is not compensated. In view of the scope for damage compensation, according to first chapter, Article 113 in Contract Law, "the party does not fulfill the contract's obligations or fulfill those obligations while not conforming to the agreement, further to cause damages to the opposite, the compensation should be equal to the loss caused by breach of contract, including benefits to be obtained after fulfillment of contract, which should not surpass the possible loss that the party breaching the contract may foresee or should foreseen while signing the contract." The carrier should make compensations for direct damages to passengers caused by flight delay, including accommodation expense of passenger while waiting for another flight, passenger's loss of missing the next stopping place, extra expense for buying air ticket of other airline. Of course, it is possible that some passenger cannot sign an important contract due to unreasonable flight delay or undertakes the responsibility for breach of contract because he cannot fulfill the contract with others. 
However, according to the predictable rule of compensation for breach of contract, such a loss is usually not incorporated in the damage compensation scope of aviation carrier.

\section{COMPENSATION LIABILITY LIMIT}

According to compensation liability limit system for aviation transportation delay in Warsaw Convention, compensation for damages caused by delay is limited. In 1999, the Montreal Convention specified that the compensation limit for delay of passenger airline was 4150 Special Drawing Rights (SDRS) for each passenger. Article 131 of Civilian Aviation Law specifies that, "as related lawsuit about loss happening in the aviation transportation, no matter what is the basis, it can only be put forward in accordance with the conditions and compensation responsibilities stipulated in the law." In February 2006, Regulations on International Aviation Transportation Carrier's Compensation Liability Limit has not singly developed compensation limit for flight delay. Development trend of World's Aviation Law is inclined to protect the legal rights of passengers, the weak group. However, the current civilian aviation laws and regulations in China have made no specific response. The author suggests that the domestic flight delay compensation should implement the two-tier limit: the first tier, the compensation limit below the twice the par value, (considering the development reality of China's aviation transportation, passengers usually buy air tickets with different discounts. In order to balance bilateral benefits to the most extent, it is quite rational to take the twice limit of par value as the demarcation point of two-tier compensation). There is no need to undertake the responsibility of providing evidence within this limit (principle: the carrier undertakes liability without fault). The second tier, the compensation limit above (including) twice the par value. Within this limit, it needs to undertake the responsibility of proving evidence while compensating passengers (principle: the carrier undertakes the liability for fault).

\section{REFERENCES}

[1] Yang Hui, Wu Tongshui: "on domestic passenger flights were delayed several legal issues and related law perfect", Hebei Law , 2005, No. 8, P.66.

[2] Zhao Weitian: "International Air Law", Social Science Literature Press, 2000, P349.

[3] Dong Nianqing: "domestic air transport flight delays in the law",

[EB/OL]http://www.carnoc.com/txtm/article/2004-06-29. [4] Cai Donghui: "air passenger transport flight delay and its legal liability", Law Apply, 2006, No. 8, P.60.

[5] He Yuanhua: "on the issue of air transport unreasonable delay and its responsibility", Journal of Civil Aviation Flight University of China, 2002, No. 3, P17. 